Case Report

\title{
Primary Villoglandular Mucinous Adenocarcinoma of the Vulva
}

\author{
Akiko Matsuzaki, ${ }^{1,2}$ Masanao Saio, ,,2 Noritake Kosuge, ${ }^{1,2}$ Hajime Aoyama, ${ }^{1,2}$ \\ Tomoko Tamaki, ${ }^{1,2}$ Hirofumi Matsumoto, ${ }^{1,2}$ and Naoki Yoshimi ${ }^{1,2}$ \\ ${ }^{1}$ Division of Pathology, Ryukyu University Hospital, University of the Ryukyus, Okinawa, Japan \\ ${ }^{2}$ Department of Tumor Pathology, Faculty of Medicine, University of the Ryukyus, Okinawa, Japan \\ Correspondence should be addressed to Akiko Matsuzaki; ammatsu@med.u-ryukyu.ac.jp
}

Received 31 October 2016; Revised 3 March 2017; Accepted 4 April 2017; Published 19 April 2017

Academic Editor: Lubos Holubec

Copyright ( 2017 Akiko Matsuzaki et al. This is an open access article distributed under the Creative Commons Attribution License, which permits unrestricted use, distribution, and reproduction in any medium, provided the original work is properly cited.

\begin{abstract}
Primary villoglandular mucinous adenocarcinoma of the vulva is rare tumor. We report a case of 68-year-old woman who developed this very uncommon malignant tumor. Immunohistochemical examination of this tumor revealed positive staining for Cytokeratin 20, Mucin 2, and CDX2, although Cytokeratin 7 and Mucin 6 were negative. This positive staining indicated the tumor enteric type characters. In order to exclude the possibility of the metastasis from another site, we thoroughly evaluated clinical data and extensively investigated the whole body. However, we could not detect any other tumors. The patient was treated by tumor resection. The patient remains free of disease 5 years after surgery.
\end{abstract}

\section{Introduction}

Primary adenocarcinomas of the vulva are rare and especially the villoglandular mucinous adenocarcinoma of intestinal type is rare variant of vulvar adenocarcinoma. In the 4th edition of WHO classification of tumors of female reproductive organs, primary villoglandular mucinous adenocarcinoma is defined as a primary invasive glandular epithelial tumor of intestinal type and the synonyms are cloacogenic carcinoma or cloacogenic adenocarcinoma [1]. In the published articles [2], intestinal type mucinous adenocarcinoma was also taken as a synonymous with villoglandular mucinous adenocarcinoma. Villoglandular mucinous adenocarcinoma arises in the surface epithelium of the vulva. Only few cases have been reported to date [1-12]. The possibility that those tumors may originate from cloacal remnants has been raised [2-12]. In fact, it has been mentioned that misplaced cloacal remnants could be found in vulva. There is the hypothesis that such misplaced remnants transformed into a tubulovillous adenocarcinoma of enteric type. But still the mechanisms of development of villoglandular mucinous adenocarcinoma in vulva are controversial. Here we report the case of this rare disease.

\section{Clinical Presentation}

A 68-year-old woman had a vulvar lump with mild local discomfort. She had no relevant medical history. She came to our hospital. On physical examination, a $4 \mathrm{~cm}$ nodular yellowish lesion on the vestibule under the orifice of the urethra was seen and vulvar biopsy was taken. The mass occupied the one-third of the vestibule from right side to left side. The pelvic examination showed no other mass. The chest roentgenograph, abdominal $\mathrm{CT}$, and colonoscopy were within reference range. The specimen of the vulvar biopsy was diagnosed vulvar adenocarcinoma. Then the patient was treated by vulvar tumor resection. The tumor was surgically staged as a TisN0. She remains well and free of disease 5 years after surgery.

\section{Pathological Findings}

Grossly, the resected tumor from vestibule of vagina was papillomatous nodule, $4 \times 2 \mathrm{~cm}$ in size and yellowish in color (Figure 1). Microscopic examination of paraffin-embedded sections (Figure 2) disclosed villous adenomatous tumor in continuity with the epidermis. The cells were columnar with 


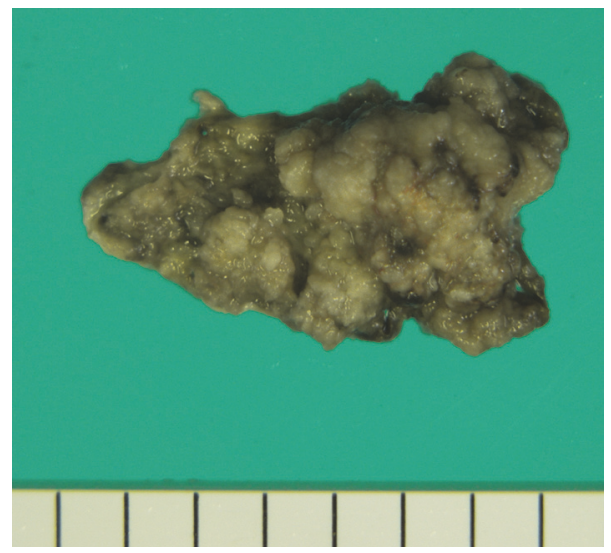

FIGURE 1: Surgical specimen showing the papillomatous, yellowish nodular lesion measuring $4 \times 2 \mathrm{~cm}$.

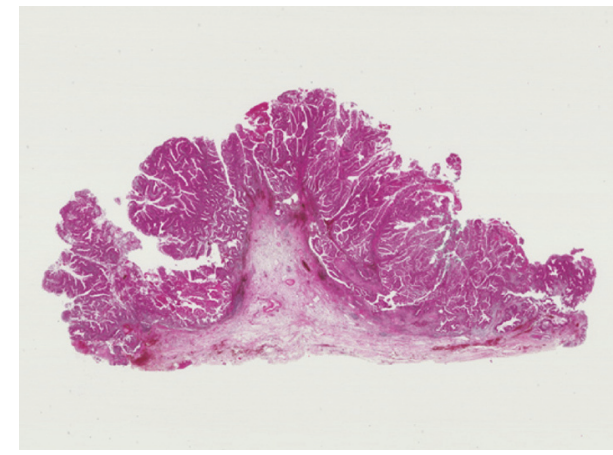

(a)

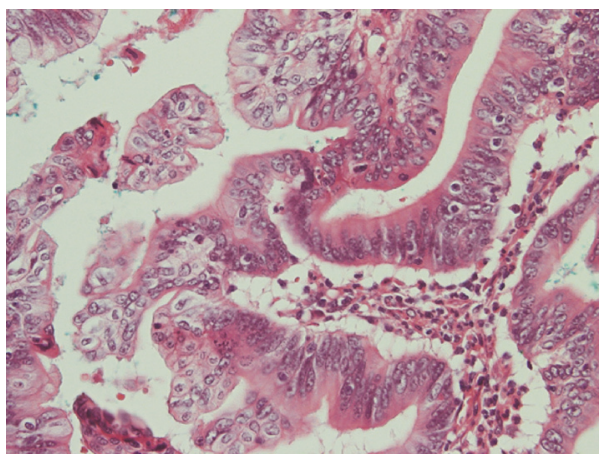

(c)

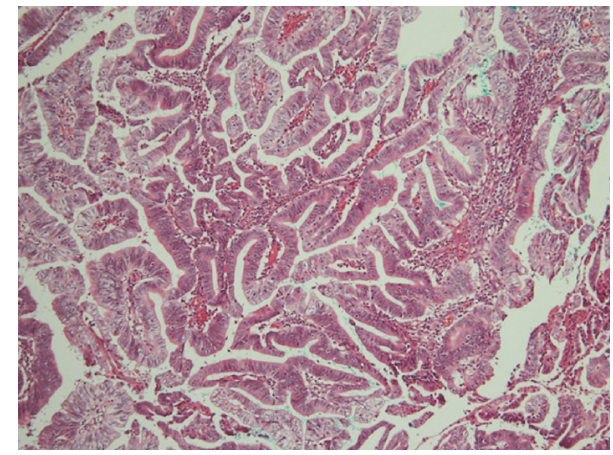

(b)

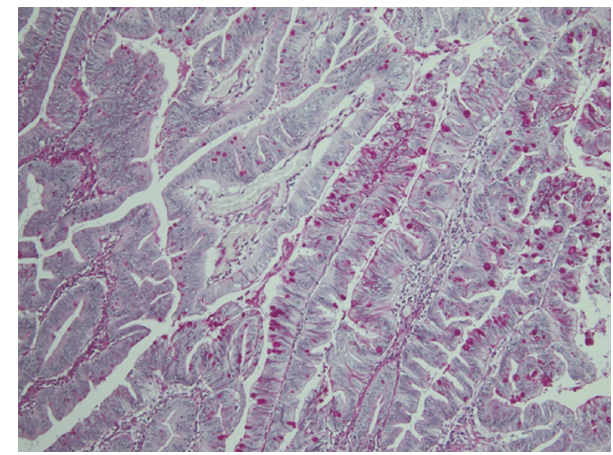

(d)

FIGURE 2: (a) Low-power view of the tumor shows papillomatous nodule. No tumor invasion was seen. HE staining. (b) Villous adenomatous tumor is observed. HE staining. (c) Tumor cells show high-grade nuclear atypia. (d) PAS staining shows positive staining for the goblet cells.

ovoid nuclei, often stratified and sometimes proliferating into gland-in-gland pattern. The cells lost their normal basal polarity. The brush borders were observed. The small amount of goblet cells was seen but Paneth's cells were not detected. The tumor had a large proportion of mitotic cells and its resemblance to adenocarcinoma of the large intestine was striking. The high proportion of mitotic cells and resemblance to well-differentiated adenocarcinoma of the large intestine suggested that this neoplasm was adenocarcinoma rather than adenoma. No invasion or no microinvasion of the tumor cells was seen.
Immunostains and PAS stains (Figures 2 and 3) were performed. Immunostains used a routine techniques with antibodies against the following antigens: Cytokeratin (CK) 7 (Dako, Glostrup, Denmark), CK20 (Dako), Mucin 2 (MUC2) (LAB VISION, Fremont, CA, USA), MUC6 (LAB VISION), CDX2 (BioGenex, San Ramon, CA, USA), and MIB-1 (Dako). In most neoplastic cells, prominent positive immunohistochemical staining for CK20, MUC2, and CDX2 was identified. CK7 and MUC6 did not demonstrate any reactivity. These data showed that these neoplastic cells had enteric type character. MIB-1 stain for nuclear antigen in proliferating 


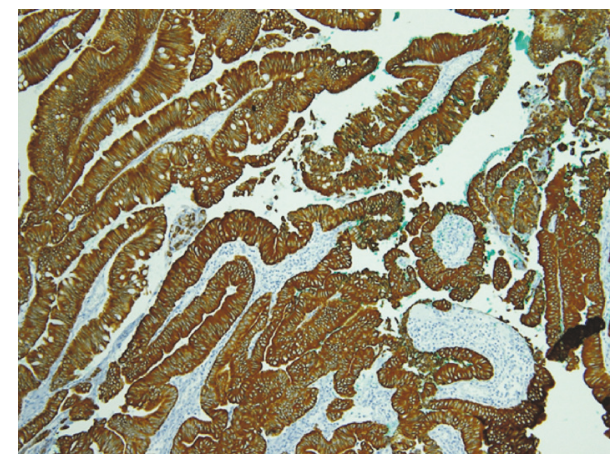

(a)

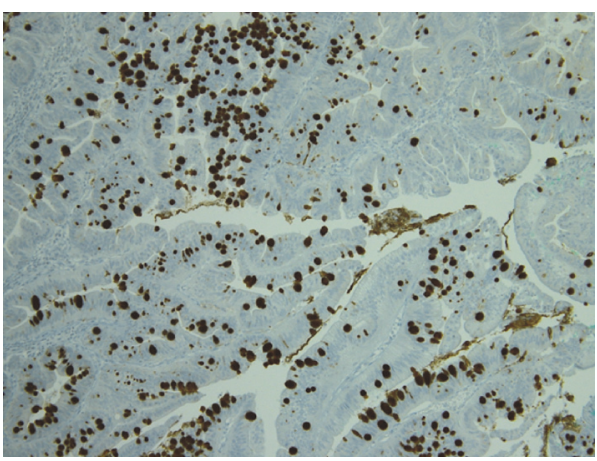

(c)

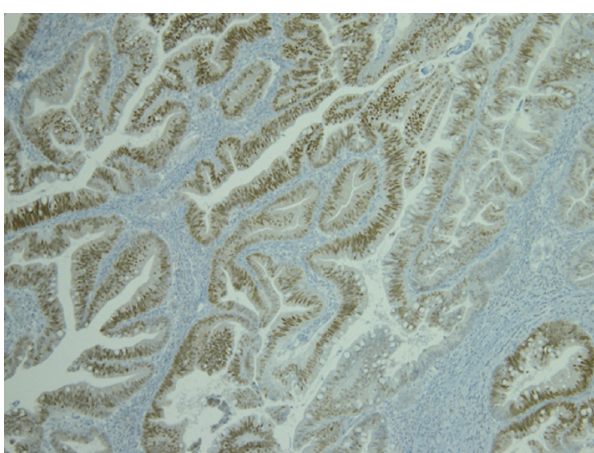

(e)

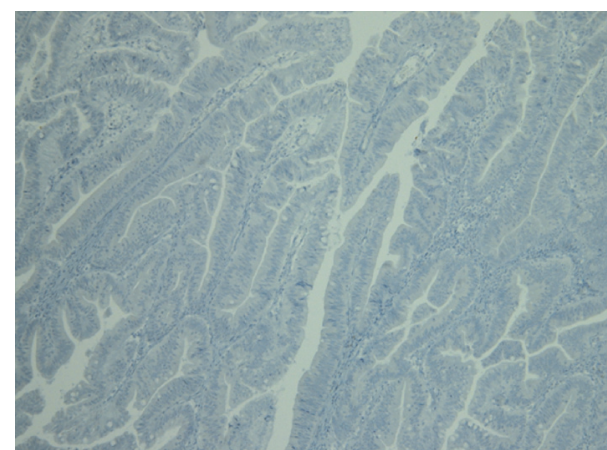

(b)

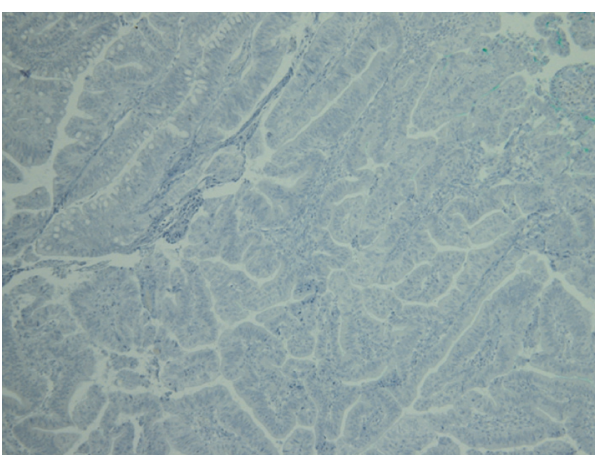

(d)

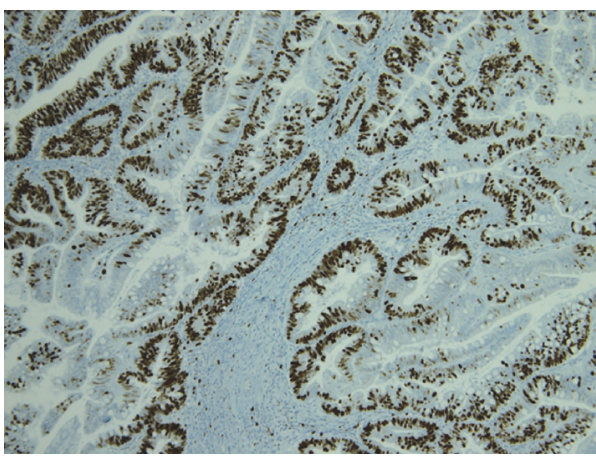

(f)

Figure 3: Immunohistochemical feature of the tumor cells. (a, b) Almost all tumor cells are positive for (a) CK20, but the cells are negative for (b) CK7. (c, d) Major proportion of tumor cells is positive for (c) MUC2, but expression of (d) MUC6 is negative. (e) CDX2 is positive for the nucleus of the tumor cells. (f) $40-50 \%$ of tumor cells are positive for MIB1.

cells showed a high proportion (more than 50\%) of MIB1 positive cells indicating an intense cellular proliferation. High proportion of MIB-1 positive cells suggested that this neoplasm was adenocarcinoma rather than adenoma. In [11], Karkouche et al. suggested that cellular atypia and high mitotic index indicate the intramucosal adenocarcinoma instead of adenoma. Pathologically our case was carcinoma in situ, and TNM stage was Tis.

\section{Discussion}

This is the case report of rare, vulva primary villoglandular mucinous adenocarcinoma in situ. This disease is more commonly known as adenocarcinoma of cloacogenic origin, enteric type adenocarcinoma, or cloacogenic adenocarcinoma [1-12]. Villoglandular adenocarcinomas are more frequent in the colon and rectum. The possibility that this lesion might be metastatic has been ruled out by a complete negative clinical workup. The precious mechanism of the development of enteric tumors in the female genital tracts is not known. However, since the lower vagina is derived from the urogenital tract, enteric neoplasia of the lower genital tract could develop from loci of gastrointestinal metaplasia from cloacal remnants. There are several reports of enteric type adenocarcinoma and adenoma in the vulva [1-13] (Table 1). These reports have supported the hypothesis that enteric neoplasia of the vulva could develop from loci of cloacal remnants. Similar enteric type adenoma and adenocarcinoma of the 
TABLE 1: Reported cases of enteric type tumor in female lower genital tract.

\begin{tabular}{|c|c|c|c|c|c|c|}
\hline Authors & Age & Location & Histology & Immunohistochemistry & Follow-up & Ref. \\
\hline Tiltman and Knutzen & 50 & Vulva & Adenocarcinoma & Not done & 1 year & [3] \\
\hline \multirow{2}{*}{ Kennedy and Majmudar } & 54 & Vulva & Adenocarcinoma & $\mathrm{CEA}-\mathrm{CK}+$ & 10 years & \multirow{2}{*}{ [4] } \\
\hline & 63 & Vulva & Adenocarcinoma & Not done & 4 years & \\
\hline \multirow{2}{*}{ Ghamande et al. } & 80 & Vulva & Adenocarcinoma & CEA+ & 19 months & \multirow{2}{*}{ [5] } \\
\hline & 67 & Vulva & Adenocarcinoma & $\mathrm{CEA}+$ & 17 months & \\
\hline Willén et al. & 57 & Vulva & Adenocarcinoma & $\mathrm{CEA}+, \mathrm{CK}+$ & 26 months & [6] \\
\hline Rodriguez et al. & 69 & Vulva & Adenocarcinoma & $\begin{array}{c}\mathrm{CEA}+, \mathrm{CK} 7+, \\
\mathrm{CK} 20+, \mathrm{ER}-\mathrm{PR}-\end{array}$ & 36 months & [7] \\
\hline Zaidi and Conner & 43 & Vulva & Adenocarcinoma & $\mathrm{CEA}+, \mathrm{CK}+$ & 18 months & [8] \\
\hline Liu et al. & 49 & Vulva & Adenocarcinoma & Not done & 24 months & {$[9]$} \\
\hline Dubé et al. & 58 & Vulva & Adenocarcinoma & $\begin{array}{l}\mathrm{CK} 7+, \mathrm{CK} 20+ \\
\mathrm{CEA}+\end{array}$ & 16 months & [10] \\
\hline Cormio et al. & 58 & Vulva & Adenocarcinoma & CK7+ & Death & {$[2]$} \\
\hline & 42 & Vulva & Adenocarcinoma & $\begin{array}{l}\text { CK20+/- } \\
\text { Adenomas; }\end{array}$ & 39 months & \\
\hline Karkouche et al. & 31 & Vulva & $\begin{array}{l}\text { Adenomas and } \\
\text { adenocarcinoma }\end{array}$ & $\begin{array}{c}\text { CK7-/CK20+ } \\
\text { Adenocarcinoma; } \\
\text { Not done }\end{array}$ & & [11] \\
\hline Vitrey et al. & 57 & Vulva & Adenocarcinoma & $\begin{array}{c}\text { CK7-CK20+ } \\
\text { CDX2+, CA125+/- }\end{array}$ & 17 months & {$[12]$} \\
\hline Musella et al. & 66 & Vulva & Tubulovillous adenoma & Not done & N/A & {$[13]$} \\
\hline Ciano et al. & 72 & Vagina & Villous adenoma & Not done & 6 months & {$[14]$} \\
\hline Ulbright et al. & 5 & Vagina & Papilloma & Not done & 12 months & {$[15]$} \\
\hline \multirow{2}{*}{ Fox et al. } & 35 & Vagina & $\begin{array}{c}\text { Enteric } \\
\text { adenocarcinoma }\end{array}$ & Not done & N/A & \multirow[t]{2}{*}{ [16] } \\
\hline & 59 & Vagina & $\begin{array}{c}\text { Enteric } \\
\text { adenocarcinoma }\end{array}$ & Not done & N/A & \\
\hline Mortensen and Nielsen & 43 & Vagina & Tubulovillous adenoma & CEA & N/A & [17] \\
\hline Nagar et al. & 45 & Vagina & Adenocarcinoma & $\begin{array}{c}\mathrm{CK}+, \mathrm{CEA}+, \mathrm{p} 53+ \\
\mathrm{ER}-, \mathrm{PR}-\end{array}$ & 18 months & {$[18]$} \\
\hline Mudhar et al. & 56 & Vagina & Adenocarcinoma & CK7-, CK20+, CEA+ & 18 months & [19] \\
\hline Werner et al. & $\begin{array}{l}67 \\
45\end{array}$ & $\begin{array}{l}\text { Vagina } \\
\text { Vagina }\end{array}$ & $\begin{array}{l}\text { Adenocarcinoma } \\
\text { Adenocarcinoma }\end{array}$ & $\begin{array}{c}\text { CK7-, CK20-, } \\
\text { CEA+ } \\
\text { CK7+, CK20-, CEA- }\end{array}$ & $\begin{array}{l}14 \text { months } \\
23 \text { months }\end{array}$ & [20] \\
\hline Dubé et al. & 64 & Vagina & Adenocarcinoma & CK7+, CK20+ & 18 months & [21] \\
\hline Lee et al. & 61 & Vagina & Tubulovillous adenoma & 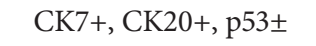 & N/A & {$[22]$} \\
\hline Tjalma and Colpaert & 55 & Vagina & Adenocarcinoma & $\mathrm{CK} 7+, \mathrm{CK} 20+$ & N/A & [23] \\
\hline van Wessel et al. & 68 & Vagina & Adenocarcinoma & $\mathrm{CEA}+, \mathrm{CK} 20+, \mathrm{CK} 7+$ & 25 months & {$[24]$} \\
\hline
\end{tabular}

Ref.; reference. N/A; not available.

vagina and cervix were published [14-24]. Also this hypothesis is supported by several reports of villous adenoma and enteric type adenocarcinoma of the urologic system such as the bladder and urethra $[25,26]$. Other possible mechanisms of enteric type tumor developed in the female genital tract are (1) intestinal metaplasia occurrence in tissue of Mullerian origin or (2) congenital ectopic intestinal epithelium of the urogenital tract as a result of embryological error. The use of immunohistochemical techniques has opened new perspectives in studying the primary villoglandular adenocarcinoma of the vulva. In general, the staining pattern of CK7-/CK20+ is the greatest proportion in colorectal carcinoma. And it is our case. Also, mucin pattern, MUC2+/MUC6-, suggested the colorectal carcinoma mucin pattern [27]. CDX1 and CDX2 are aberrantly expressed in intestinal metaplasia. The expression of CDX1 and CDX2 is closely associated with the expression of MUC2. In our case, both MUC2 and CDX2 were strong positive. These data clearly show that the character of this villoglandular mucinous adenocarcinoma is colorectal type. The histologic differential diagnosis of this case should include other types of vulva adenocarcinomas, such as adenocarcinoma of mammary gland type, adenocarcinoma of sweat gland type, and Bartholin gland carcinoma. Adenocarcinoma of mammary gland type has been reported 
as mammary-like ductal carcinoma or lobular carcinoma, morphologically and immunohistochemically different from our case. Sweat gland type adenocarcinoma and Bartholin gland carcinoma are also morphologically different from our case. These adenocarcinomas are deeply infiltrative and in situ carcinoma should be in these glands.

In all described villoglandular mucinous adenocarcinomas of vulva [1-12], the clinical behavior of this rare malignant neoplasm seems to be rather indolent, and patients are generally doing well, after either radical vulvectomy or wide local excision. Until we have further experience, tumor location, size, and microscopic appearance should determine the type of surgery. Good cooperation between clinician and pathologist is required for the determination of type of surgery. Bilateral inguinal lymph node dissection has been performed in the reported cases $[5,10]$ and no lymph node metastasis was reported. Despite apparent low risk of metastasis, we should discuss whether ipsilateral or bilateral inguinal lymph node dissection is required or not, because our knowledge for this tumor is still limited due to experience.

In conclusion, both pathologists and clinician should be aware of the existence of this rare tumor. However, more cases are needed to fully understand its origin and to establish its long-term prognosis.

\section{Disclosure}

The current address of Masanao Saio is Matsunami General Hospital, Gifu, Japan.

\section{Conflicts of Interest}

The authors declare that they have no conflicts of interest.

\section{Acknowledgments}

Professor M. Yasuda, Department of Pathology, Saitama Medical University International Medical Center, is gratefully acknowledged for reviewing this case and making valuable suggestions.

\section{References}

[1] R. J. Kurman, M. L. Carcangiu, C. S. Herrington, and R. H. Young, WHO Classification of Tumours of Female Reproductive Organs, IARC Press, Lyon, France, 2011.

[2] G. Cormio, C. Carriero, V. Loizzi et al., "'Intestinal-type’ mucinous adenocarcinoma of the vulva: a report of two cases," European Journal of Gynaecological Oncology, vol. 33, no. 4, pp. 433-435, 2012.

[3] A. J. Tiltman and V. K. Knutzen, "Primary adenocarcinoma of the vulva originating in misplaced cloacal tissue," Obstetrics and Gynecology, vol. 51, no. 1, pp. 30-33, 1978.

[4] J. C. Kennedy and B. Majmudar, "Primary adenocarcinoma of the vulva, possibly cloacogenic: a report of two cases," Journal of Reproductive Medicine for the Obstetrician and Gynecologist, vol. 38, no. 2, pp. 113-116, 1993.
[5] S. A. Ghamande, J. Kasznica, C. T. Griffiths, N. J. Finkler, and A. M. Hamid, "Mucinous adenocarcinomas of the vulva," Gynecologic Oncology, vol. 57, no. 1, pp. 117-120, 1995.

[6] R. Willén, Z. Békássy, B. Carlén, B. Bozoky, and S. Cajander, "Cloacogenic adenocarcinoma of the vulva," Gynecologic Oncology, vol. 74, no. 2, pp. 298-301, 1999.

[7] A. Rodriguez, M. A. Isaac, E. Hidalgo, B. Márquez, and F. F. Nogales, "Villoglandular adenocarcinoma of the vulva," Gynecologic Oncology, vol. 83, no. 2, pp. 409-411, 2001.

[8] S. N. Zaidi and M. G. Conner, "Primary vulvar adenocarcinoma of cloacogenic origin," Southern Medical Journal, vol. 94, no. 7, pp. 744-746, 2001.

[9] S.-H. Liu, C.-M. Ho, S.-H. Huang, B.-Y. Shih, and F.-K. Lee, "Cloacogenic adenocarcinoma of the vulva presenting as recurrent Bartholin's gland infection," Journal of the Formosan Medical Association, vol. 102, no. 1, pp. 49-51, 2003.

[10] V. Dubé, C. Veilleux, M. Plante, and B. Têtu, "Primary villoglandular adenocarcinoma of cloacogenic origin of the vulva," Human Pathology, vol. 35, no. 3, pp. 377-379, 2004.

[11] R. Karkouche, F. Ansart, B. Terris, M. C. Lavenu, and F. Plantier, "Multiple tubulovillous adenomas of the vulva," American Journal of Dermatopathology, vol. 34, no. 3, pp. 321-324, 2012.

[12] D. Vitrey, S. Frachon, B. Balme, and F. Golfier, "Tubulovillous adenoma of the vulva," Obstetrics and Gynecology, vol. 102, no. 5, pp. 1160-1163, 2003.

[13] A. Musella, C. Marchetti, L. Salerno et al., "An unexpected complete remission of advanced intestinal-type vulvar adenocarcinoma after neoadjuvant chemotherapy: a case report and a literature review," Case Reports in Obstetrics and Gynecology, vol. 2013, Article ID 427141, 5 pages, 2013.

[14] P. S. Ciano, D. A. Antonioli, J. Critchlow, L. Burke, and H. Goldman, "Villous adenoma presenting as a vaginal polyp in a rectovaginal tract," Human Pathology, vol. 18, no. 8, pp. 863$866,1987$.

[15] T. M. Ulbright, R. W. Alexander, and F. T. Kraus, "Intramural papilloma of the vagina: evidence of Müllerian histogenesis," Cancer, vol. 48, no. 10, pp. 2260-2266, 1981.

[16] H. Fox, M. Wells, M. Harris, L. J. Mcwilliam, and G. S. Anderson, "Enteric tumours of the lower female genital tract: a report of three cases," Histopathology, vol. 12, no. 2, pp. 167$176,1988$.

[17] B. B. Mortensen and K. Nielsen, "Tubulo-villous adenoma of the female genital tract: a case report and review of literature," Acta Obstetricia et Gynecologica Scandinavica, vol. 70, no. 2, pp. 161-163, 1991.

[18] H. A. Nagar, K. A. McKinney, J. H. Price, H. R. McClelland, and J. D. Biggart, "Enteric epithelium progressing through dysplasia to adenocarcinoma within the vagina," European Journal of Surgical Oncology, vol. 25, no. 1, pp. 106-107, 1999.

[19] H. S. Mudhar, J. H. F. Smith, and J. Tidy, "Primary vaginal adenocarcinoma of intestinal type arising from an adenoma: case report and review of the literature," International Journal of Gynecological Pathology, vol. 20, no. 2, pp. 204-209, 2001.

[20] D. Werner, E. J. Wilkinson, D. Ripley, and A. Yachnis, "Primary adenocarcinoma of the vagina with mucinous-enteric differentiation: a report of two cases with associated vaginal adenosis without history of diethylstilbestrol exposure," Journal of Lower Genital Tract Disease, vol. 8, no. 1, pp. 38-42, 2004.

[21] V. Dubé, G. M. Lickrish, K. N. MacNeill, and T. J. Colgan, "Villoglandular adenocarcinoma in situ of intestinal type of the hymen: de novo origin from squamous mucosa?" Journal of Lower Genital Tract Disease, vol. 10, no. 3, pp. 156-160, 2006. 
[22] S. E. Lee, N. H. Park, I. A. Park, S. B. Kang, and H. P. Lee, "Tubulo-villous adenoma of the vagina," Gynecologic Oncology, vol. 96, no. 2, pp. 556-558, 2005.

[23] W. A. A. Tjalma and C. G. A. Colpaert, "Primary vaginal adenocarcinoma of intestinal type arising from a tubulovillous adenoma," International Journal of Gynecological Cancer, vol. 16, no. 3, pp. 1461-1465, 2006.

[24] S. van Wessel, H. Van Kerrebroeck, V. Van Bogaert, P. Tummers, and R. Van den Broecke, "Primary intestinal type adenocarcinoma of the female genital tract, arisen from a tubulo-villous adenoma: case report," Gynecologic Oncology Case Reports, vol. 4, pp. 63-65, 2013.

[25] L. Cheng, R. Montironi, and D. G. Bostwick, "Villous adenoma of the urinary tract: a report of 23 cases, including 8 with coexistent adenocarcinoma," American Journal of Surgical Pathology, vol. 23, no. 7, pp. 764-771, 1999.

[26] J. L. Seibel, S. Prasad, R. E. Weiss, E. Bancila, and J. I. Epstein, "Villous adenoma of the urinary tract: a lesion frequently associated with malignancy," Human Pathology, vol. 33, no. 2, pp. 236-241, 2002.

[27] Q. Liu, M. Teh, K. Ito, N. Shah, Y. Ito, and K. G. Yeoh, "CDX2 expression is progressively decreased in human gastric intestinal metaplasia, dysplasia and cancer," Modern Pathology, vol. 20, no. 12, pp. 1286-1297, 2007. 


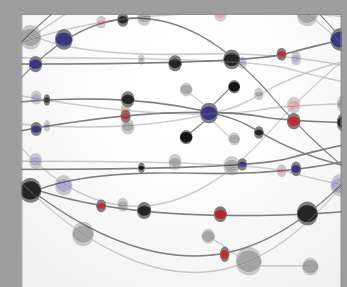

The Scientific World Journal
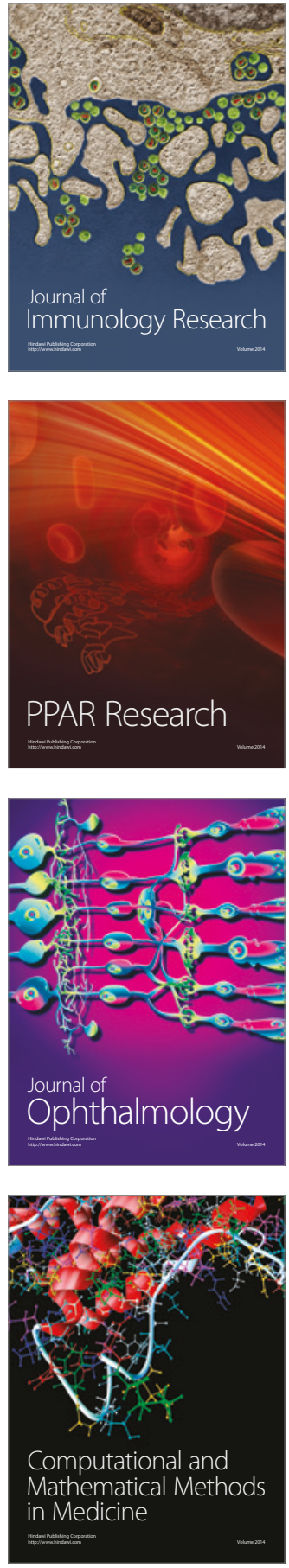

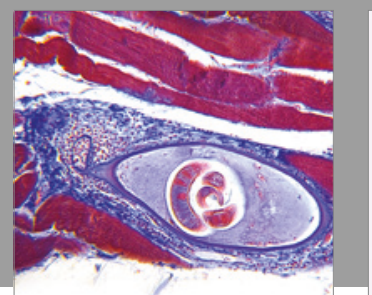

Gastroenterology Research and Practice
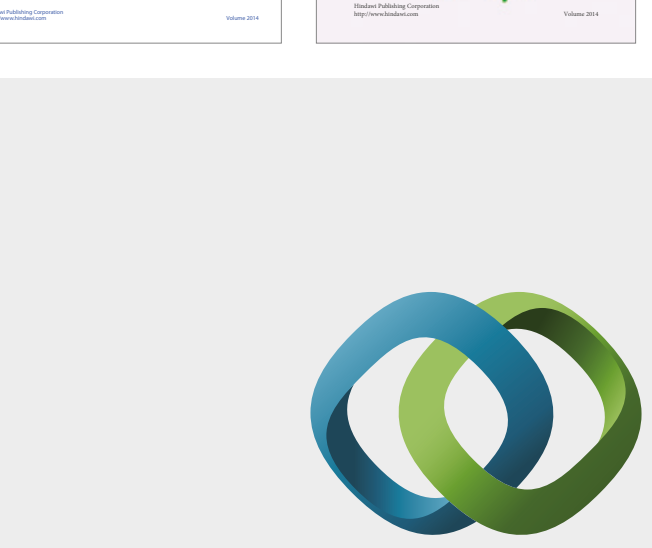

\section{Hindawi}

Submit your manuscripts at

https://www.hindawi.com
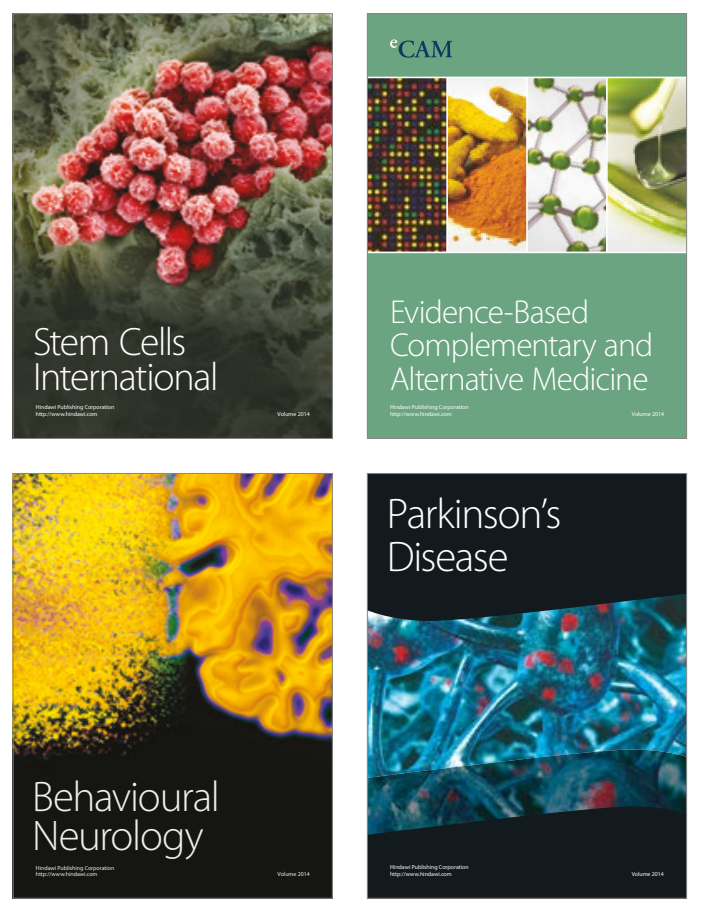
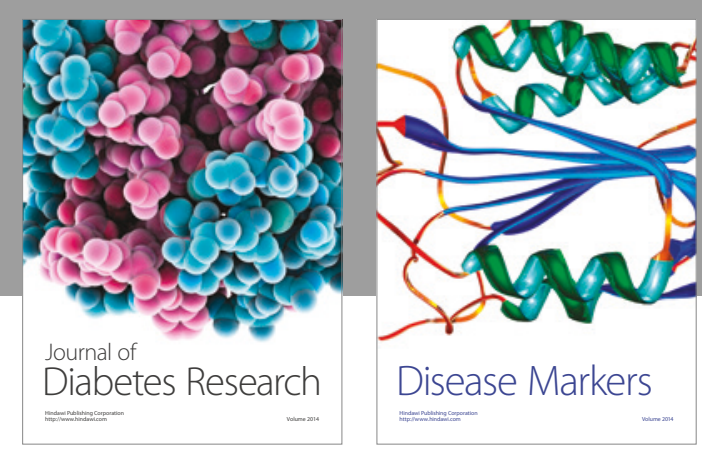

Disease Markers
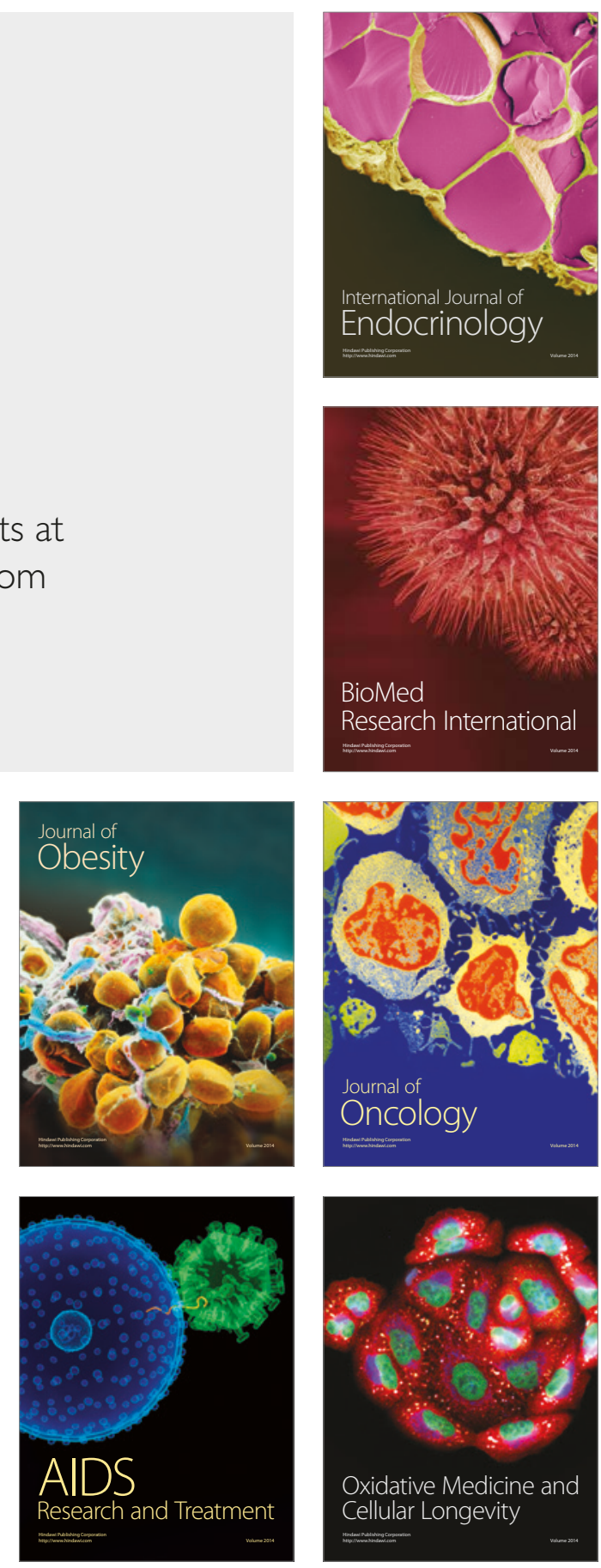